PRAKTISCHE SCHAAKLESSEN

2 
OMSLAGONTWERP: SIMON DE ZWARTE

DRUK : GEUZE DORDRECHT 
DEN HERTOG-EUWE

\title{
PRAKTISCHE SCHAAKLESSEN
}

\author{
2 \\ DOOR \\ H. J. DEN HERTOG en DR. M. EUWE
}

negende druk

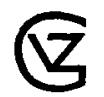

VAN GOOR ZONEN DEN HAAG 